\title{
Optimisation of backfill operations at Mavres Petres mine
}

\author{
E Palatos Hellas Gold S.A., Greece, and Eldorado Gold Corporation, Greece \\ M Yumlu Backfill Geotechnical Mining Consultants Pty Ltd, Australia
}

\begin{abstract}
Mavres Petres mine is an underground mine, located in Chalkidiki, northern Greece, that is owned and operated by Hellas Gold; a wholly owned subsidiary of Eldorado Gold Corporation. The mine extracts a high-grade lead and zinc orebody using drift and fill mining method. Backfill is an integral part of mining cycle at Mavres Petres mine. Filtered coarse tailings mixed with cement are used for making cemented hydraulic backfill in a surface batching plant. The paper will discuss and present an overview of the backfill optimisation efforts at Mavres Petres mine, which includes recent changes and upgrades in the backfill plant, improved mix design, backfill quality control, and backfill delivery and placement in order to improve the operational efficiency, product consistency, safety and economic viability of the mine.
\end{abstract}

Keywords: hydraulic backfill, coarse tailings, mix design, arched shotcrete barricades, backfill pre-support, $Q A / Q C$, test work, uniaxial compressive strength

\section{Introduction}

Mavres Petres mine is located in Chalkidiki, northern Greece, about 100 km east from Thessaloniki (Figure 1).

Mineralisation in Mavres Petres deposit is hosted in a marble layer with several south trending hydrothermal veins. The veins are characterised by a blend of massive sulphides (galena, pyrite, sphalerite) along the footwall of an active fault system (Stratoni fault). The main host rocks are amphibolite in hanging wall and marble in footwall. The orebody is accessed from footwall and the infrastructure is primarily located in gneiss and marble.

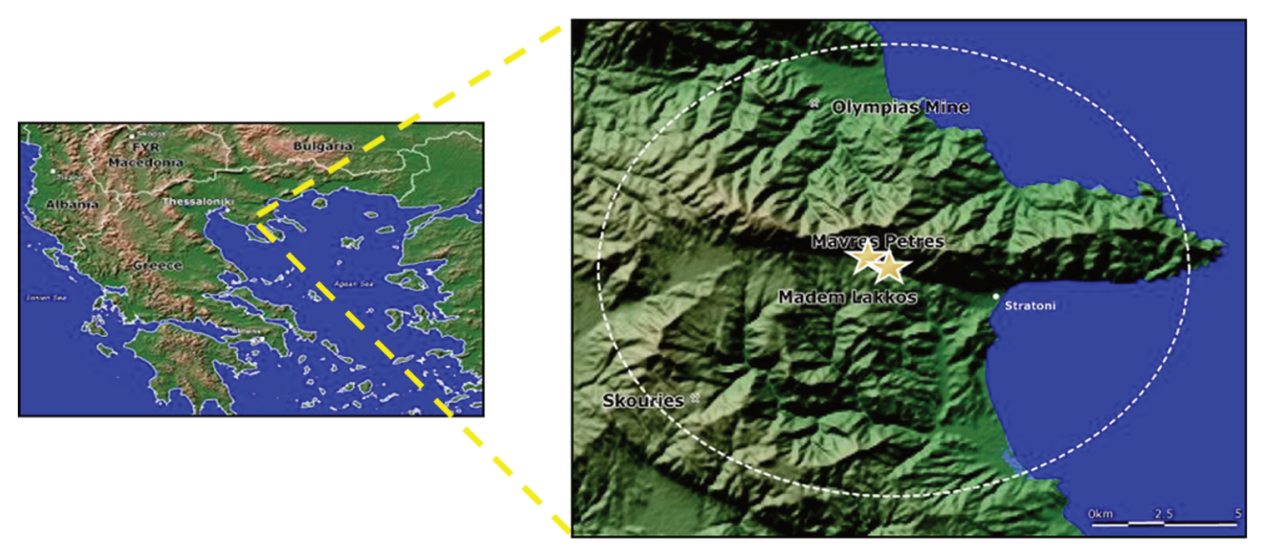

Figure 1 Mavres Petres mine location

Due to the relatively shallow dipping mineralisation (35 degrees) and the prevailing weak ground conditions, the orebody is mined using a drift and fill mining method (DAF) using backfill, in an overhand sequence. This method allows selective mining and good control of ground conditions by limiting the exposure of unsupported stope surfaces. Fill is an integral part of the mining cycle and introduced immediately following the completion of each drift. The current mining operations are approximately $500 \mathrm{~m}$ below surface.

Cemented hydraulic fill is used for making backfill in a surface batching plan. Coarse fraction of mill tailings is mixed with cement for making backfill. Tailings stockpiled on surface, screened and air dried, and delivered 
to the backfill plant. The backfill mix is pumped underground through DN125 steel pipelines. The annual backfill demand is approx. $50,000 \mathrm{~m}^{3}$ at the current ore production rate of 220,000 tonnes per year, assuming total void filling and ore density of $4.2 \mathrm{t} / \mathrm{m}^{3}$.

A comprehensive operational review was conducted to trouble shoot operational issues and identify areas of improvement in late 2018 (Backfill Geotechnical Mining Consultants Pty Ltd [BGMC] 2019). A holistic system engineering approach was adopted, which included the entire backfill system from tailings through to plant equipment, plant operation, plant maintenance, operator safety, quality control, laboratory testing and standard operating procedures, backfill delivery and placement.

The optimisation efforts are ongoing and an overview of the implemented system changes to date are provided in this paper.

\section{Backfill plant}

The backfill plant is working two 8-hour shifts per day. The backfill plant is old and has been in use for more than 20 years. Following a detailed independent review of the backfill system by BGMC, a series of tasks, actions and improvements were recommended for the backfill plant with the objective of improving operator's safety, plant capacity and efficiency while improving process control and minimising variability of backfill quality. The following tasks and improvements were implemented:

- Calibration of cement dosing system.

- Calibration of tailings weight scale.

- Calibration of water metering system.

- Replacement of the old, very basic SCADA system with a new updated one.

- General plant cleaning including sandblasting of hardened material.

- Replacement and upgrade of the steep and very narrow ladderways (Figure 2).

- Upgrade of heavily corroded platforms around the plant and cable trays (Figure 3).

- Design and installation of a new safe access platform in order to inspect and clean the oversize material inside the hopper (Figure 4).

- Replacement of the old, worn-out, flat conveyor belt of the aggregate batching system.

- Installation of a new backfill sampling valve on the pump hopper (Figure $4 b$ ).

- Installation of safety guard around the backfill mixer pulley.

- Sandblasting and major cleaning of the mixer.

- Installation of concrete brattice around backfill plant to prevent discharge to environment.

- Upgrade of the tailings feed bunker vibrators.

- Installation of pressure indication transducer device on the backfill pipeline on surface.

- Installation of a new butterfly valve with a pneumatic actuator for control of mixing water (Figure 5).

- Purchase and installation of a moisture meter for measuring moisture of tailings and solids density of backfill.

- Backfill sampling for solids density and uniaxial compressive strength (UCS) for quality control (QC).

- Setting up an onsite geotechnical lab for QC testing. 


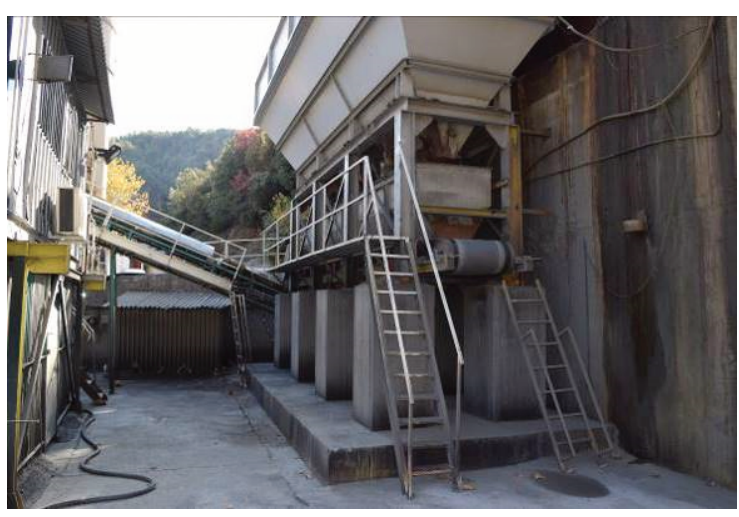

(a)

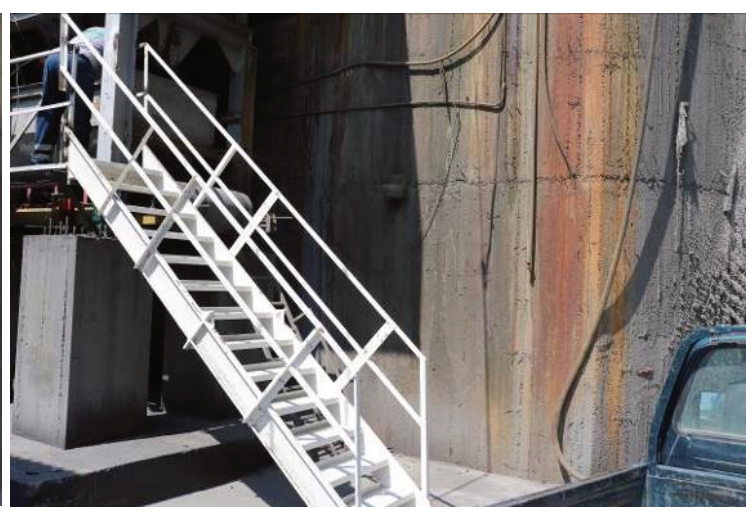

(b)

Figure 2 Replacement and upgrade of the (a) steep and very narrow ladderway with (b) new one

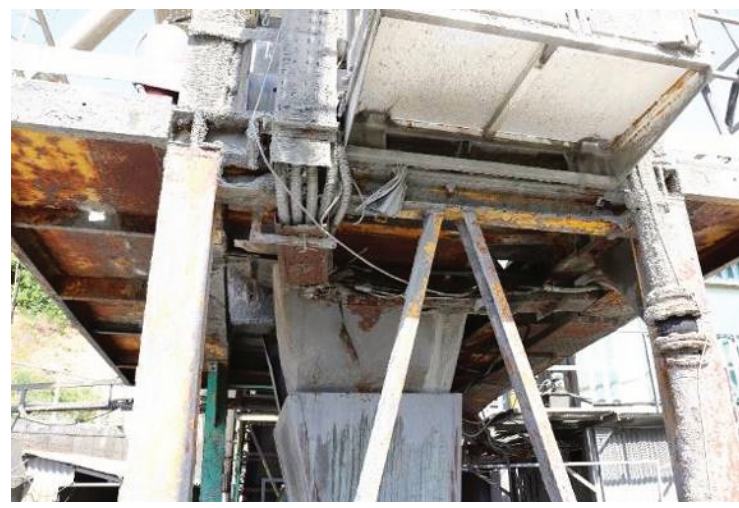

(a)

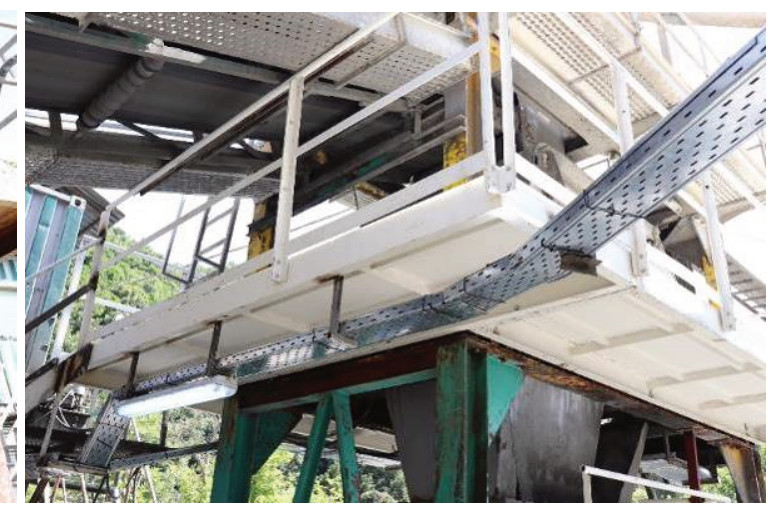

(b)

Figure 3 Replacement of the (a) heavily corroded platforms with (b) new structurally safer one

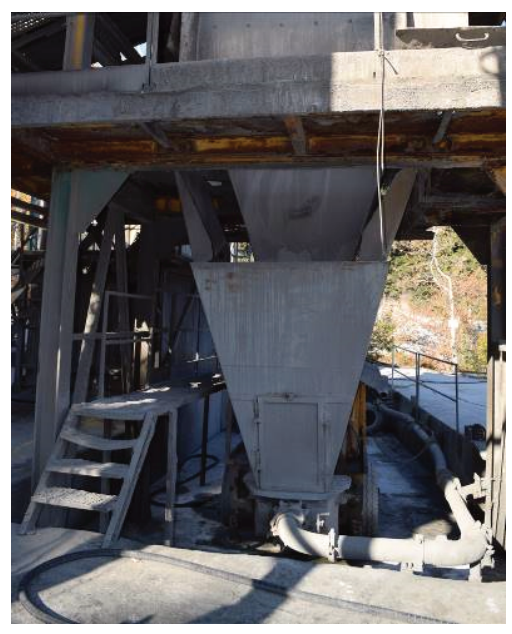

(a)

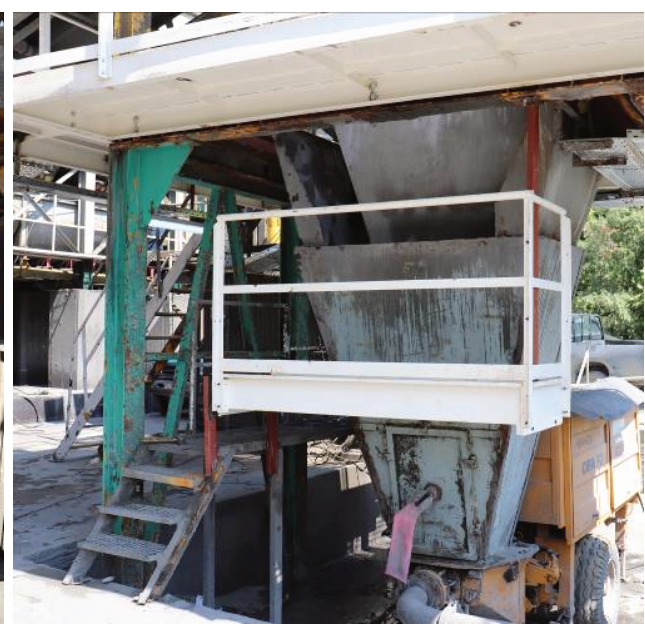

(b)

Figure 4 (a) Before and (b) after the installation of the new safe access platform for the inspection and cleaning of the oversize material inside the hopper. Also, a QC sampling valve installed on the pump hopper (b) 

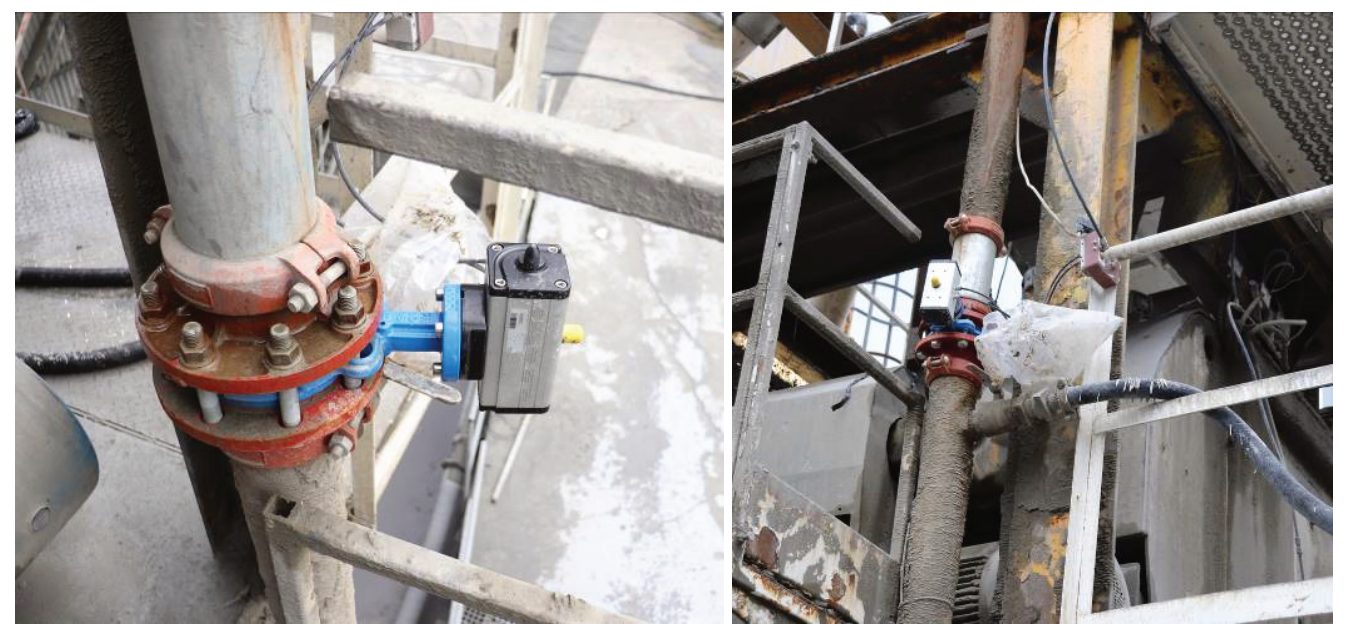

Figure 5 The new butterfly water valve with the pneumatic actuator

\section{Underground mine}

\subsection{New arched shotcrete barricade design}

Mavres Petres mine had been using flat timber barricades from the beginning of backfill operations up until September 2019 (Figure 6). Due to inadequate confidence in strength of timber walls and difficulties in maintaining QC, backfill placement had to be carefully managed with controlled filling to prevent failure and serious risk of inrushes. The barricade walls are monitored by a crew of two people during the entire filling cycle.
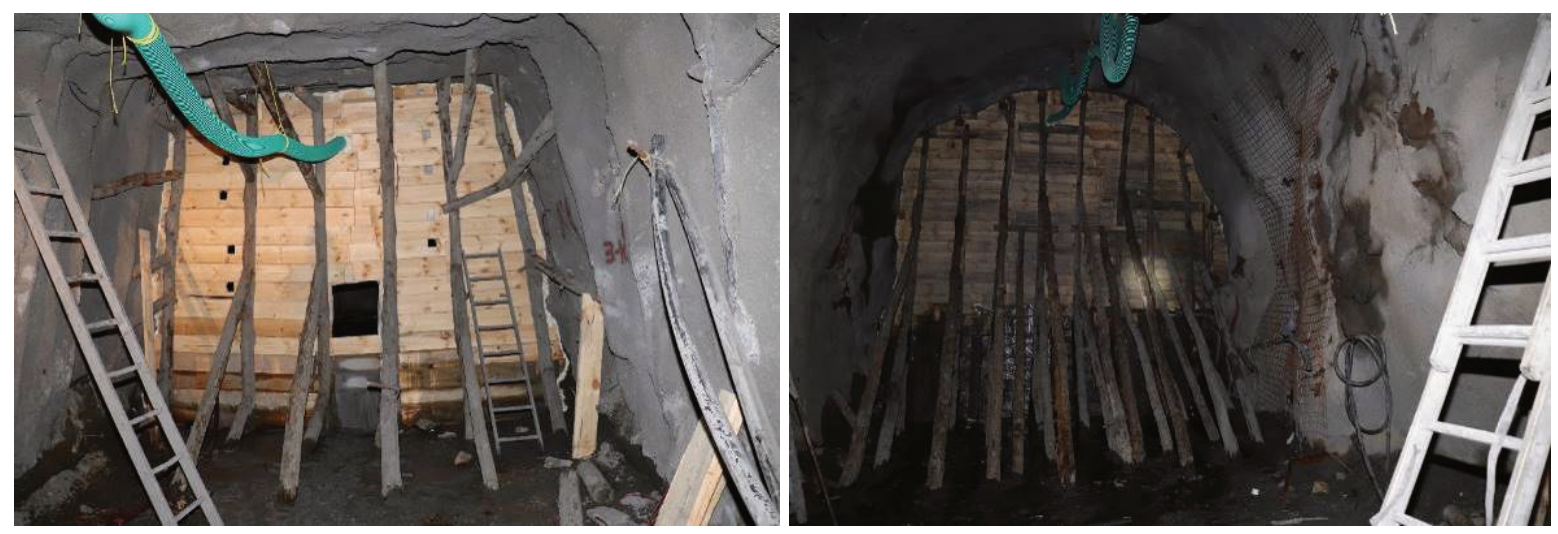

Figure 6 Flat timber backfill barricades

BGMC recommended use of engineered shotcrete barricades and an extensive test work program was initiated in June 2019, which included shotcrete UCS testing at curing ages of 1,2, 3, 5, 7, 14 and 28 days in order to fully characterise shotcrete strength at the mine. The test results are presented in Figure 7 . The early age shotcrete UCS data was used for structural analysis which estimated that $300 \mathrm{~mm}$ thick arched barricades using sprayed shotcrete will be sufficient for the expected loading conditions. The mine has successfully implemented the arched shotcrete barricade and all this period no stability issues have been observed (Figure 8). 


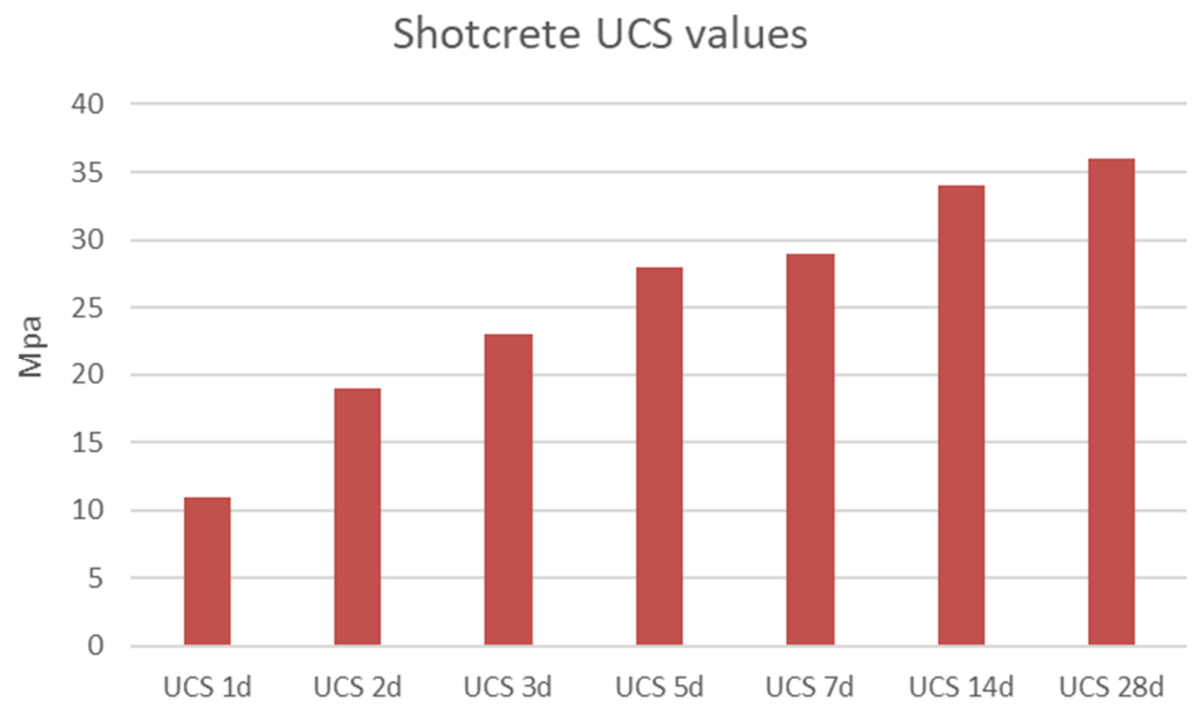

Figure 7 Shotcrete uniaxial compressive strength (UCS) results in different curing ages

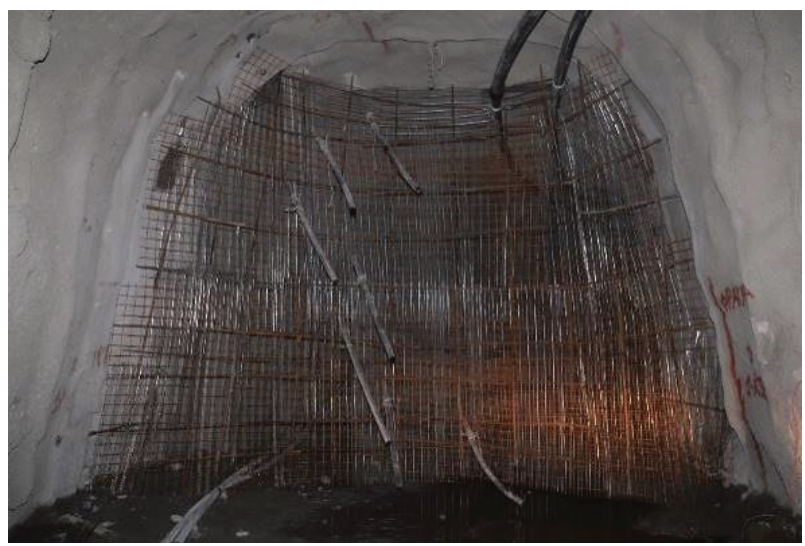

(a)

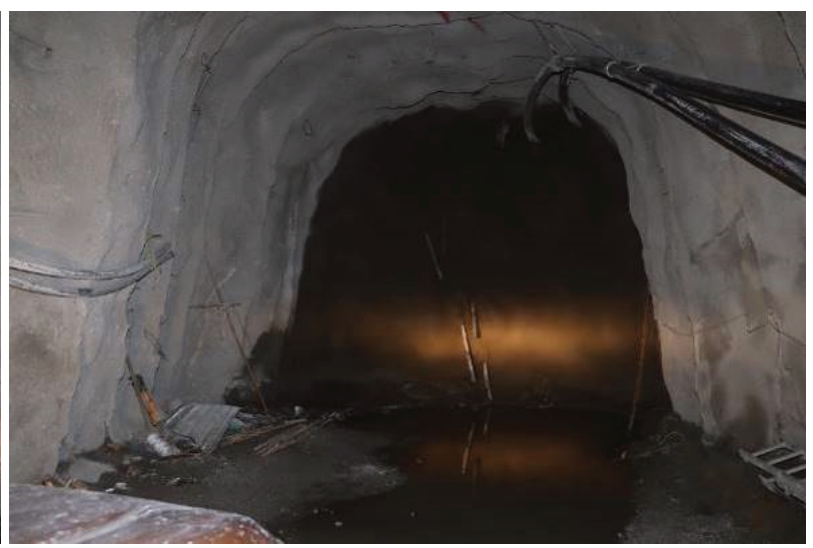

(b)

Figure 8 New arched shotcrete barricade construction (a) before shotcrete and (b) after shotcrete

The adopted shotcrete design has a higher operating capacity $(250 \mathrm{kPa})$, and this has allowed continuous filling, and minimise risk of wall failure during tight filling stage. The operating data from the initial trials indicates that the filling cycle has increased about to 2-3 times, with backfill being pumped in two shifts, non-stop, without facing any stability issues. Drainage fittings and fill drainpipes are incorporated into the design to monitor and control fill placement. Finally, the construction time of the shotcrete walls is about 2-3 shifts, which is similar to timber walls, but there is a saving of about two shifts, which was needed for dismantling and transporting timber for re-use once backfilling was complete. The mine has been using these shotcrete walls successfully as a standard practice.

\section{2 $\quad$ Filling pipes and flushing valves}

Improvements have also been made in backfill delivery reticulation pipelines. The use of green, flexible, low capacity ( 3 bar), corrugated PVC pipes (Figure 9a) have been replaced by higher capacity 16 bar HDPE pipes with a diameter of 5 in (Figure $9 \mathrm{~b}$ ) to eliminate the risk of failure during the filling cycle. Furthermore, flush valves have been installed on the fill line near the barricades (Figure 10). This means that flush water is not being sent into the stopes, which was the practice in the past. Now the backfill crew can check the flushing of the fill line before and after filling and divert all flush water away from the stope. This reduces the potential for segregation and cold joints in backfill, and improves the backfill stability when mining sill pillars formed between successive mining blocks. 


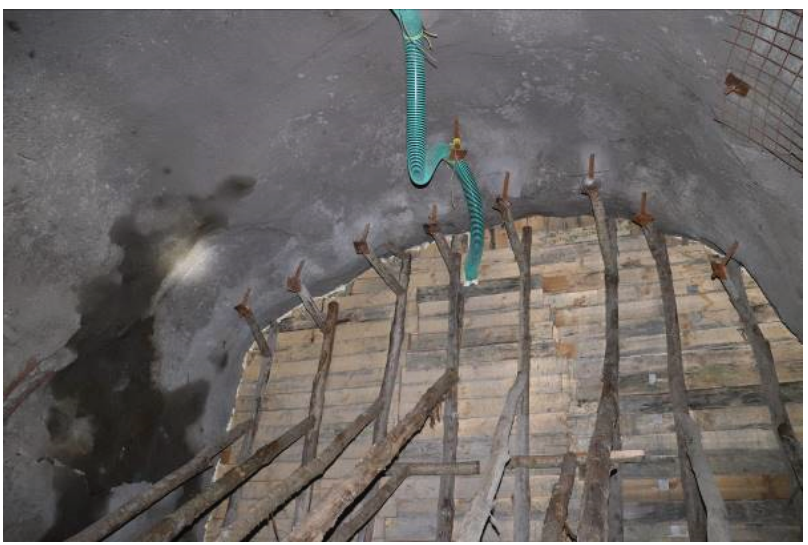

(a)

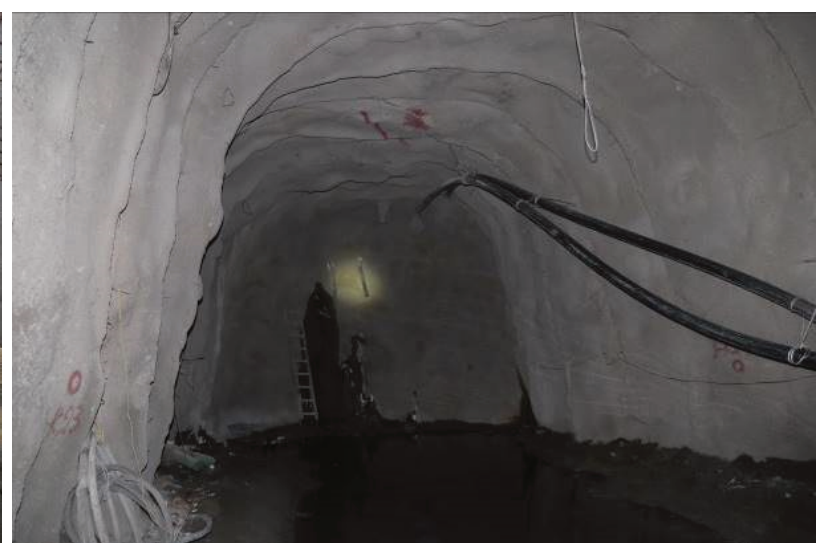

(b)

Figure 9 (a) The green flexible low capacity PVC pipe replaced by (b) black HDPE pipes of much higher capacity (16 bar)

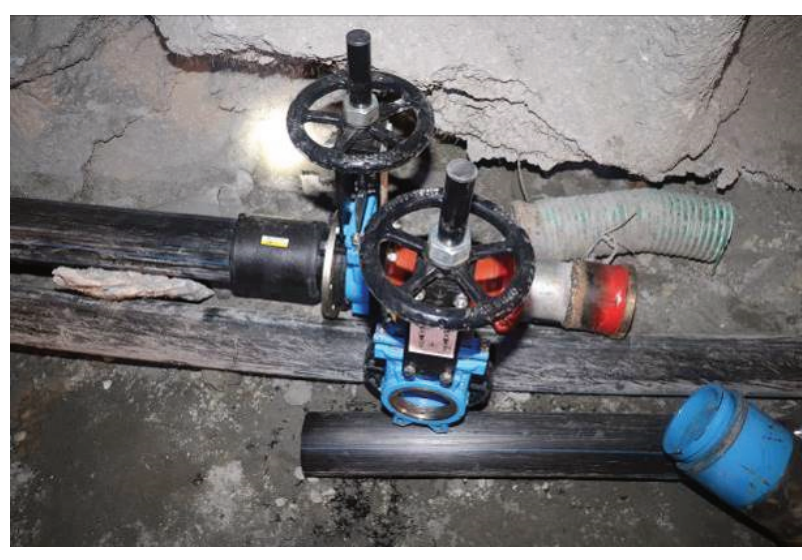

(a)

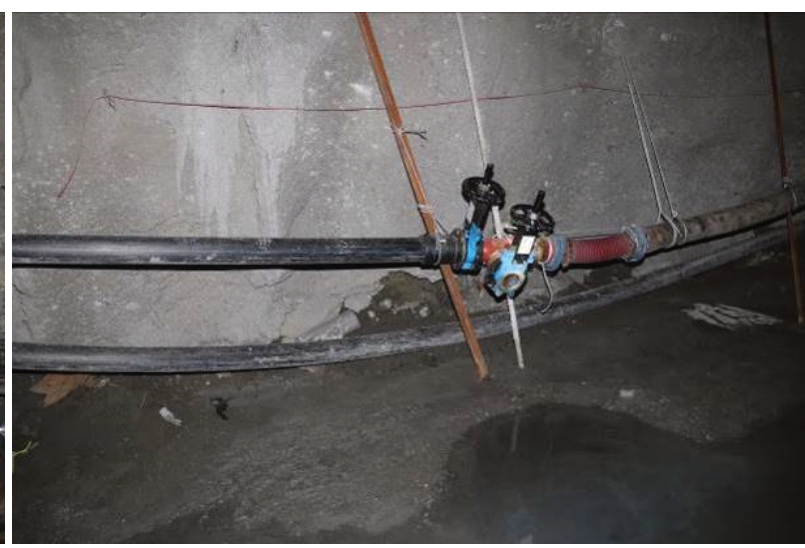

(b)

Figure 10 Knife gate flush valve installed on the fill line close to the arched shotcrete barricade (a) before filling and (b) during filling

\subsection{Sedimentation at the base of backfill pipelines}

As part of the BGMC review, some sections of lateral backfill pipelines were inspected for material build-up. It was discovered that in some areas there was a reduction in the pipe diameter due to hardened material build-up at the lower section of the pipe (Figure 11). This is due to relatively low backfill solids content, low fill velocity $(1.0-1.5 \mathrm{~m} / \mathrm{s})$ because of limited throughput rate $\left(50-55 \mathrm{~m}^{3}\right.$ per hour), and a large pipeline size (DN125).

A program of regular visual pipeline inspections for sedimentation and material build-up and cleaning the critical sections to prevent blockages has been implemented. The objective was to identify which areas are prone to build-up, so that these specific areas can be regularly inspected and cleaned. Ultrasonic thickness surveys are being scheduled on a six-monthly period to monitor pipe wear along critical sections of the pipeline. The planned wear monitoring program and database will enable the operation to predict wear rates and plan pipeline maintenance proactively in advance (Figure 12). 


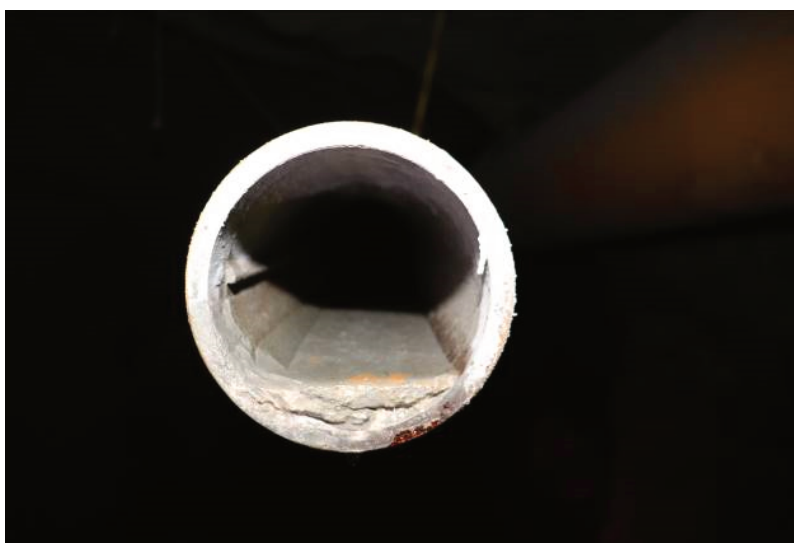

(a)

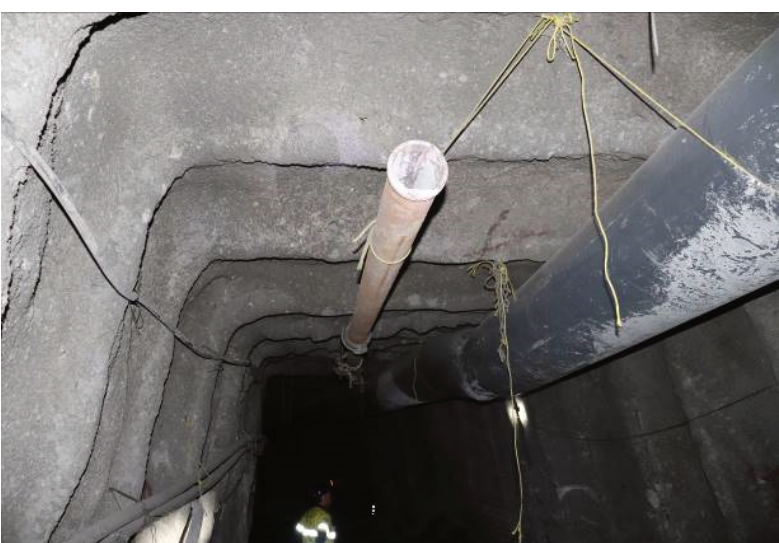

(b)

Figure 11 Sedimentation at the base of the backfill pipelines at levels (a) $120 \mathrm{E}$ and (b) 158

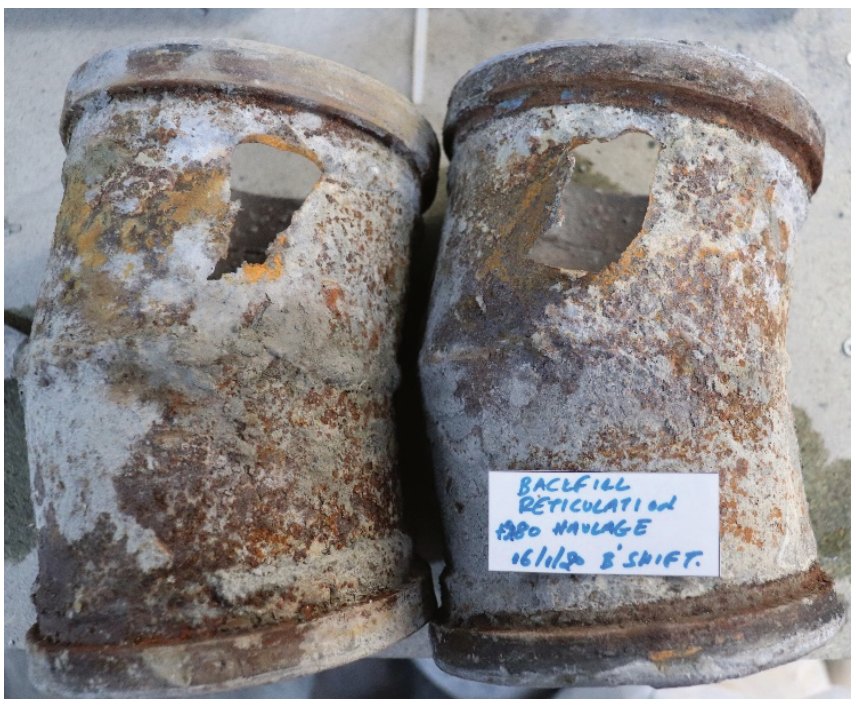

Figure 12 Failed pipes due to excessive wear

\subsection{Development of backfill pre-support for sill level stopes}

The overhand DAF stoping sequence creates sill pillars between adjacent mining blocks. Experience with recovery of sill pillars at Mavres Petres indicates that stability of backfill in sill levels is dictated mainly by presence of layering formed (cold joints and segregation) during consecutive pours. To deal with the issue of the cold joints and segregation of the hydraulic fill, Mavres Petres has implemented installing pre-support before backfilling the sill level stopes. This includes covering the floor with polyethylene membrane, installing a regular pattern of $21 \mathrm{~mm}$ diameter and $2.4 \mathrm{~m}$ long steel bars with threads on both ends in a stand-up position, with square plates $15 \times 15 \mathrm{~cm}, 5 \mathrm{~mm}$ thickness, nuts and T196 steel mesh (Figure 13a). This method has been very effective (Figure 13b) as it has improved stability and safety, as well as reduced fill dilution and increased advance rates. 


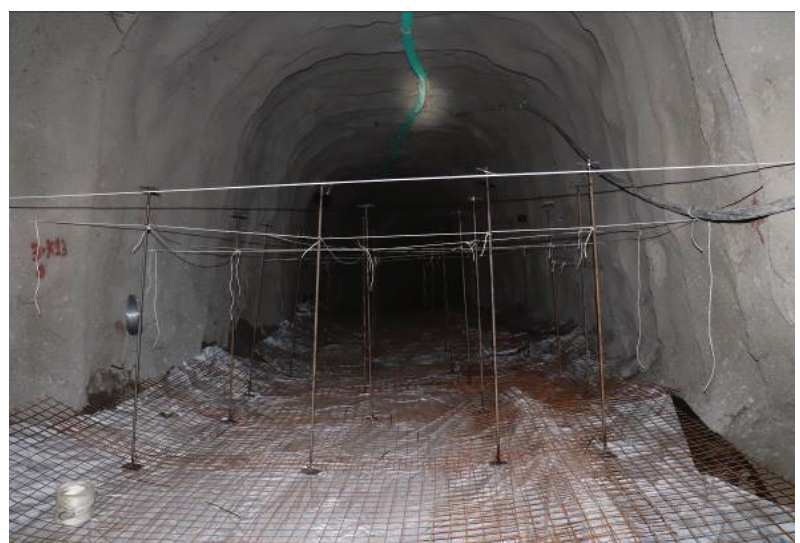

(a)

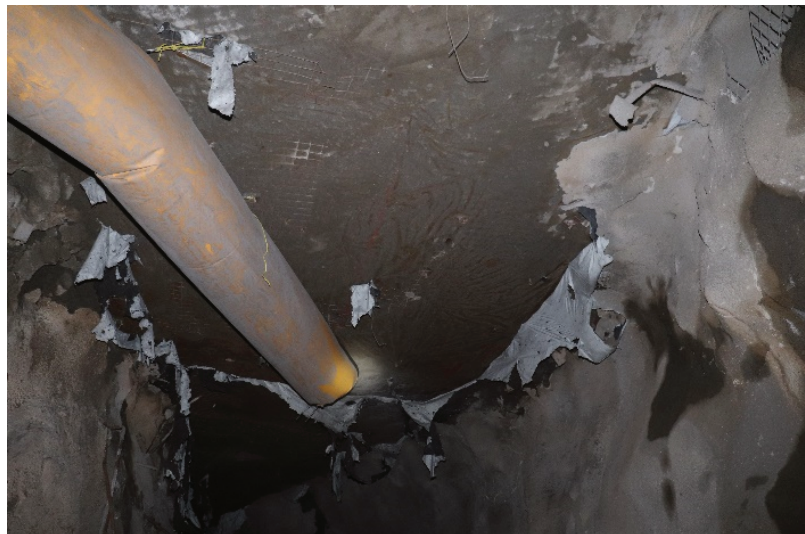

(b)

Figure 13 (a) Backfill pre-support implemented in 120E level stope panel; (b) Undercut backfill exposure with pre-support

\section{$4 \quad$ Quality assurance and quality control}

\subsection{Testing laboratory}

BGMC has recommended setting up a geotechnical lab for backfill and geotechnical testing. A modern fully equipped geotechnical laboratory that can do a wide range of test work for backfill, shotcrete, rock and soil mechanics has recently been established and has been fully functioning since June 2019 (Figure 14a). There is also a large curing chamber with power, water supply and an air-conditioning unit (Figure 14b) to keep the humidity and temperature at set conditions of $98-100 \%$ humidity and $22-24^{\circ} \mathrm{C}$ temperature. A digital probe, logs temperature and humidity for monitoring the curing conditions.

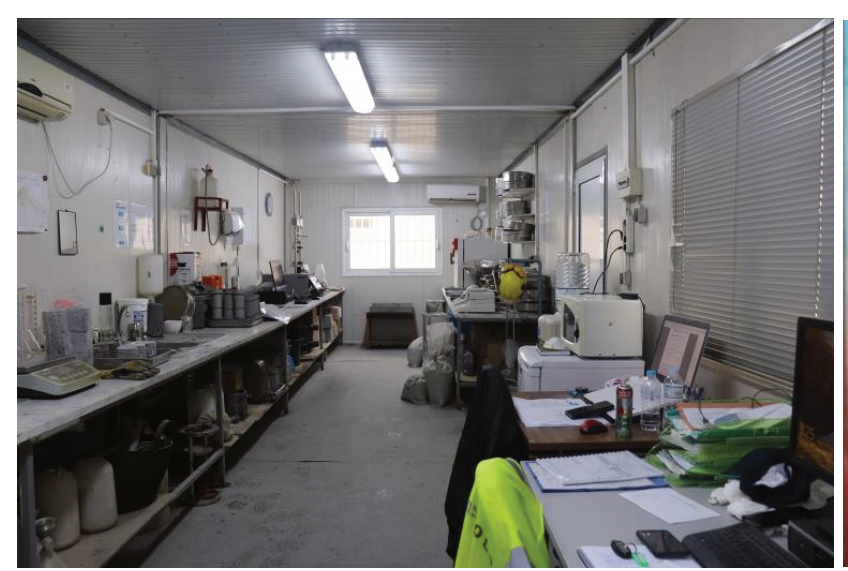

(a)

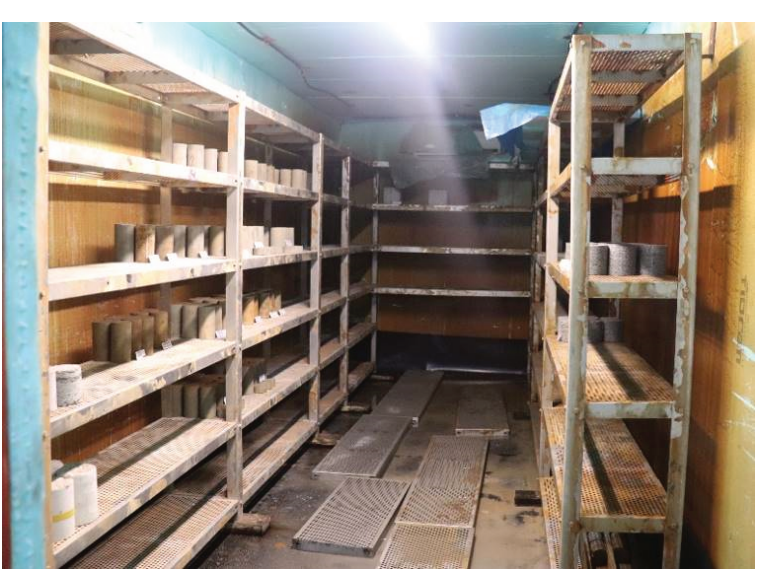

(b)

Figure 14 General view of the (a) testing laboratory and (b) curing chamber

The current laboratory equipment consists of:

- A modern compression testing press (1,500 kN capacity) which is appropriate for intact rock testing and shotcrete testing (Figure 15).

- A small capacity compression testing press (50 kN capacity) connected to PC unit for backfill testing (Figure 16).

- A rheometer connected to a PC unit (Figure 17).

- A moisture analyser for measuring moisture of tailings, backfill and shotcrete samples (Figure 18). 
- An electric hand-held mortar mixer.

- A diamond coring machine.

- A diamond saw with new universal diamond cutter heads for use with rock, shotcrete and backfill specimens.

- A number of digital scales with various weighting capacities.

- Tailings storage drums and plastic mixing buckets.

- Cubic $(150 \mathrm{~mm})$ and cylindrical moulds $(70 \times 140 \mathrm{~mm})$ for backfill and concrete sampling.

- Laboratory drying oven for the sample preparation and moisture measurements.

- A complete series of sieves for determining the particle size distribution up to 44 microns.

- Laser sizer for tailings particle size analysis installed in the mines central assay lab (Figure 19).

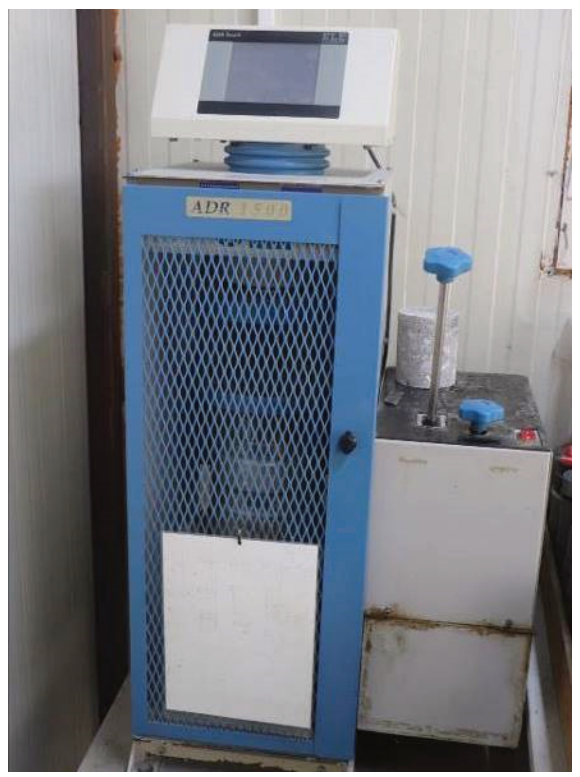

Figure 15 Uniaxial compressive strength press 1,500 kN capacity for rock, concrete, and shotcrete strength testing

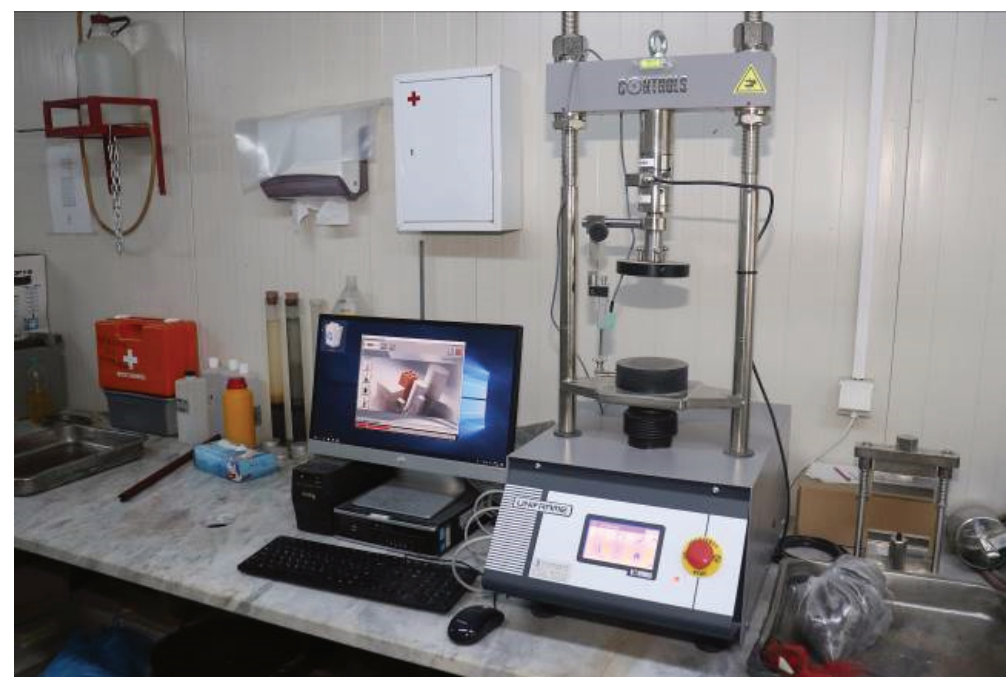

Figure 16 Uniaxial compressive strength press $50 \mathrm{kN}$ capacity for backfill strength testing 


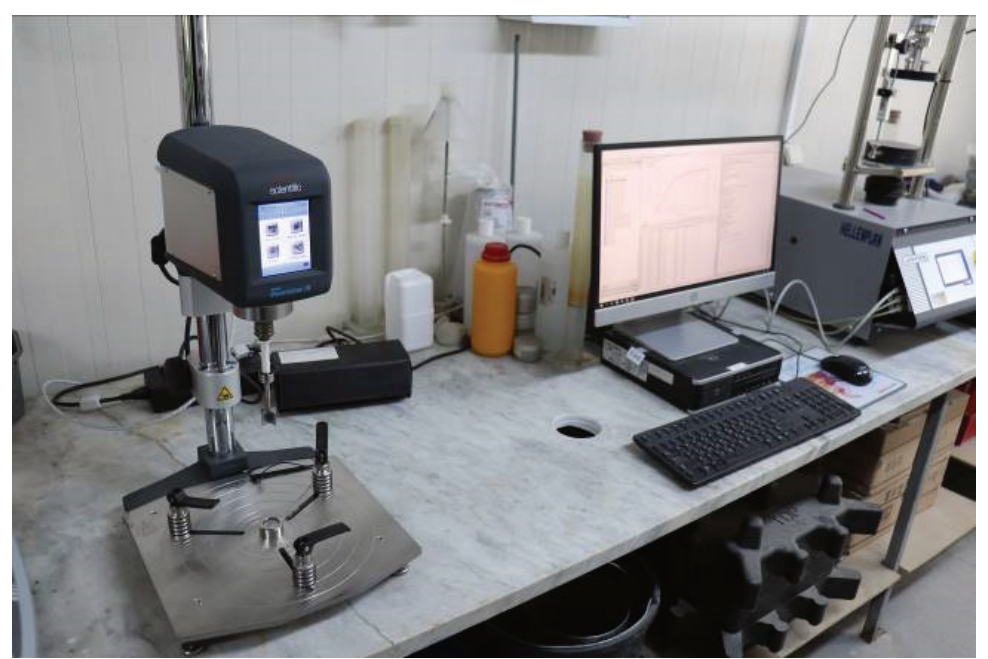

Figure 17 Rheometer connected to PC unit

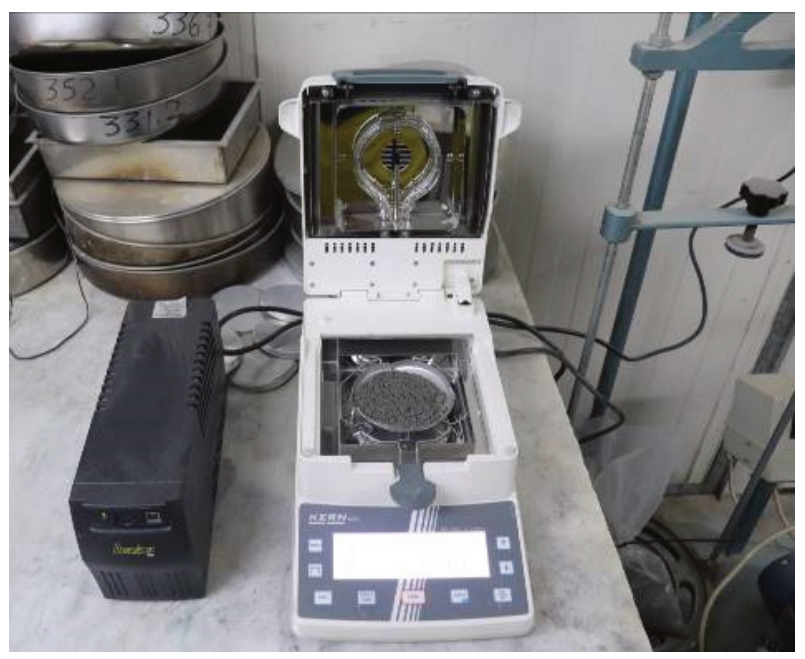

Figure 18 Moisture analyser measuring moisture of tailings

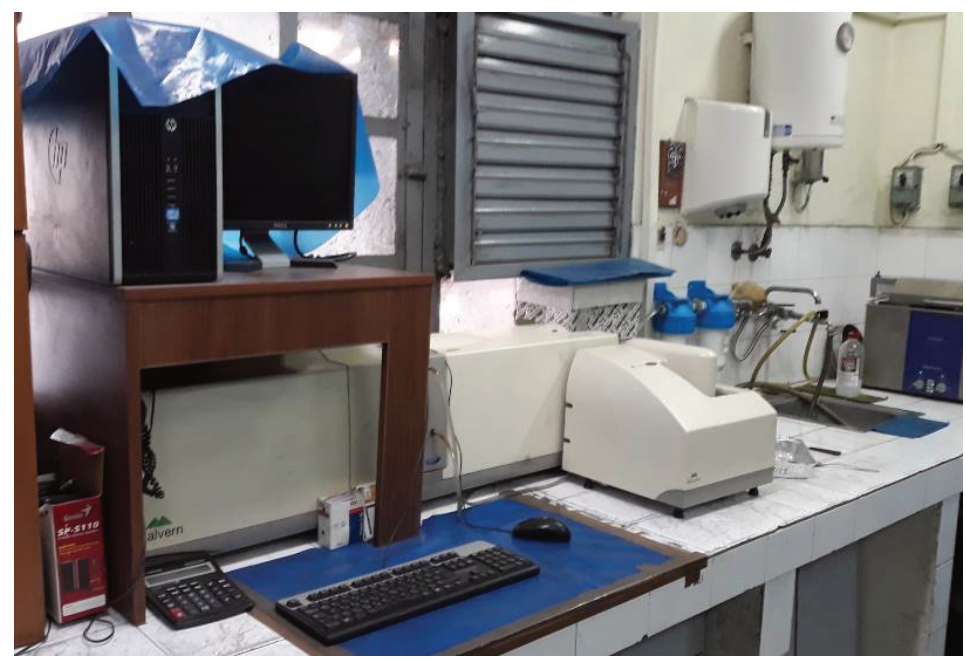

Figure 19 Lasersizer for conducting tailings particle size distribution analysis

\subsection{Backfill quality control}

A quality assurance and QC program was developed and implemented to monitor fill quality at Mavres Petres mine. 


\subsubsection{Tailings specific gravity}

A program of measuring and monitoring tailings specific gravity (SG) has been implemented since the beginning of 2019. Results indicate tailings SG varies between 3.44 and 4.10 with average SG of 3.73 and standard deviation of 0.12 (Figure 20). These results indicate variability of tailings due to changes in ore type being processed.

Tailings specific gravity

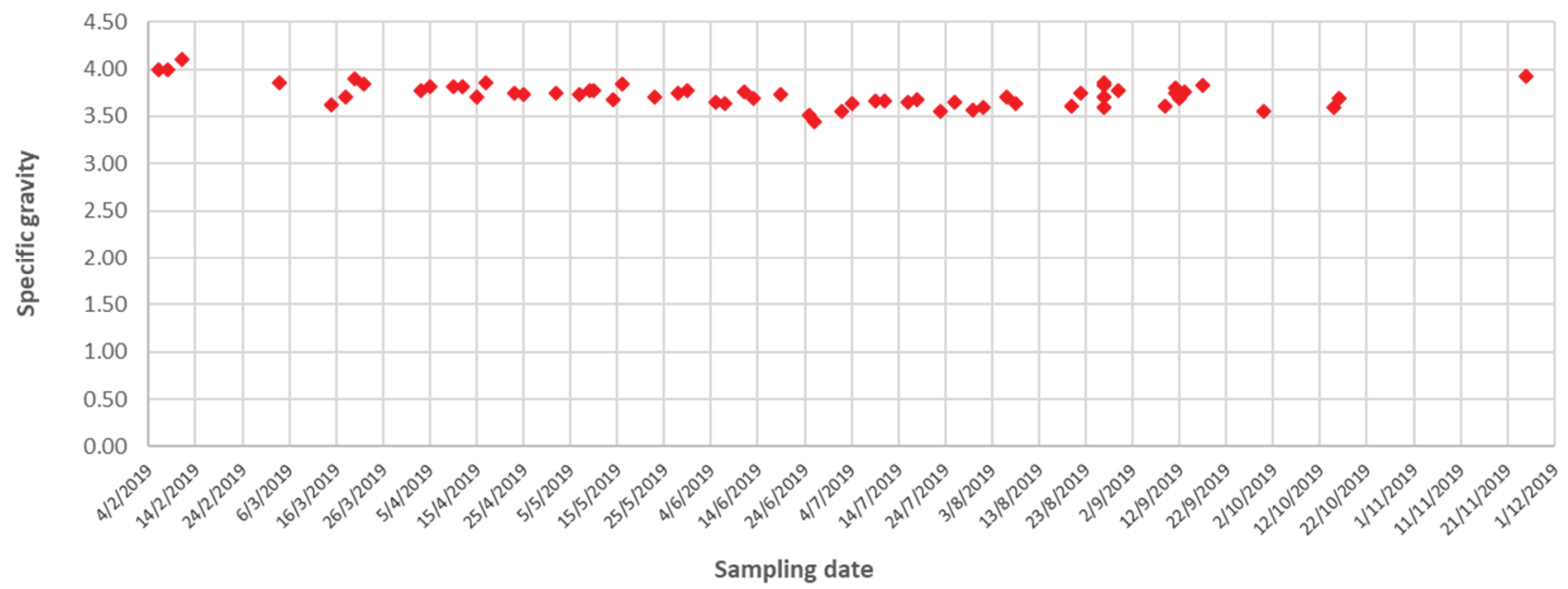

Figure 20 Tailings specific gravity variability

\subsubsection{Tailings moisture content}

Tailings moisture has been also measured consistently since the beginning of 2019, indicating an average value of $8.48 \%$ by weight and a standard deviation of $1.86 \%$. The moisture measurements indicate large variability, which is exacerbated in wet seasons during heavy rainy periods when the moisture content exceeds the value of $13 \%$ (Figure 21). Experience indicates that tailings moisture greater than $11.5 \%$ will be sticky and cause material flow issues at the backfill plant. As the tailings stockpile is not covered, the backfill plant operation is suspended when the moisture of tailings is high. Tailings is temporarily stored in a surface reclaim stockpile and the moisture of tailings is managed by screening and air-drying.

Tailings moisture content

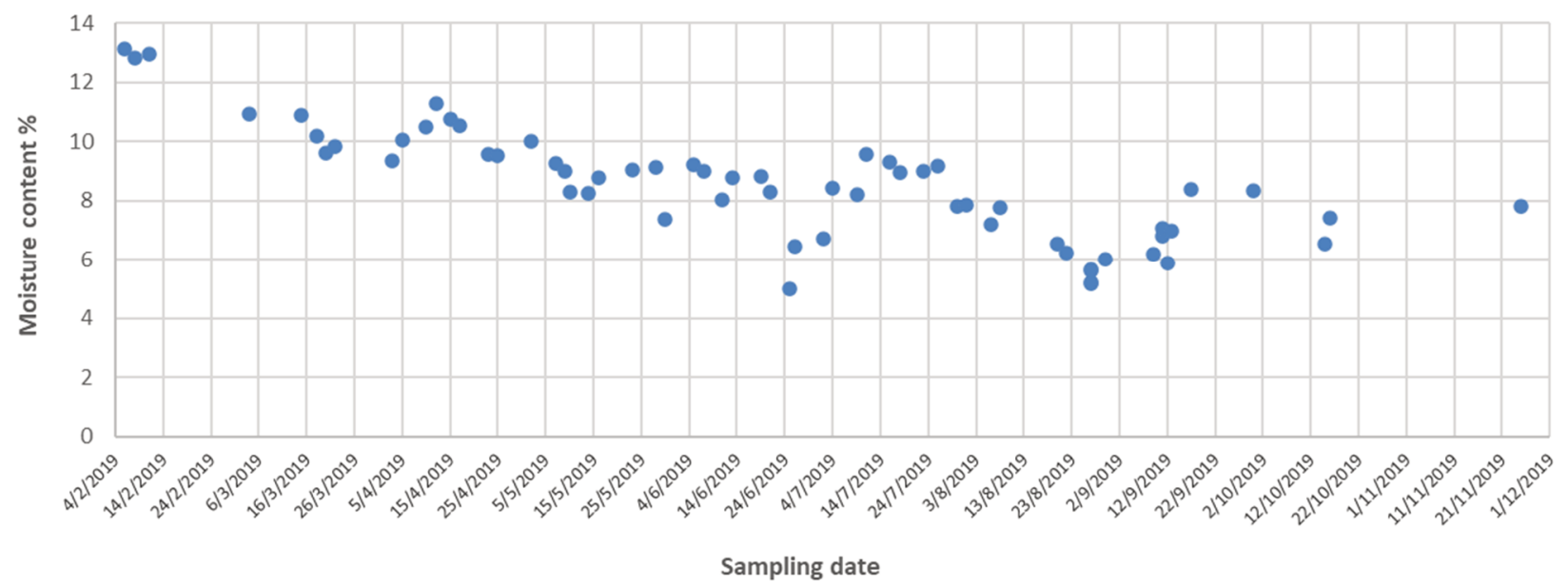

Figure 21 Tailings moisture content variability

Due to variability of tailings moisture, the backfill plant has been equipped with a moisture meter (KERN DAB 100-3), which has been used to adjust the batch mix accurately with increased confidence in rheology, pumping, and cured fill strength. The unit is very accurate, reliable, and easy to use. The operators now measure the 
moisture of tailings and backfill during backfill operations as a standard operating practice, record and report the results, consult the backfill engineer and make the required adjustments to backfill mix.

\subsubsection{Tailings particle size distribution}

Mavres Petres operates a dry stack tailings disposal system. A blend of coarse tailings are recovered from the drum filter and screw classifier at the flotation plant. Tailings particle size distribution has been measured regularly using screen analysis and Lazersizer methods. The results indicate some variability at the coarse end (P80) but still remain within the acceptable tolerance required for hydraulic fill (Figure 22). This variability could be attributed to the process variability, changes in ore type and grinding size fluctuations because of campaign milling (Monday to Friday operation). For a free draining good hydraulic fill, as a general rule of thumb, the maximum fraction of tailings passing 10 microns should not exceed 10\% (Potvin et al. 2005).

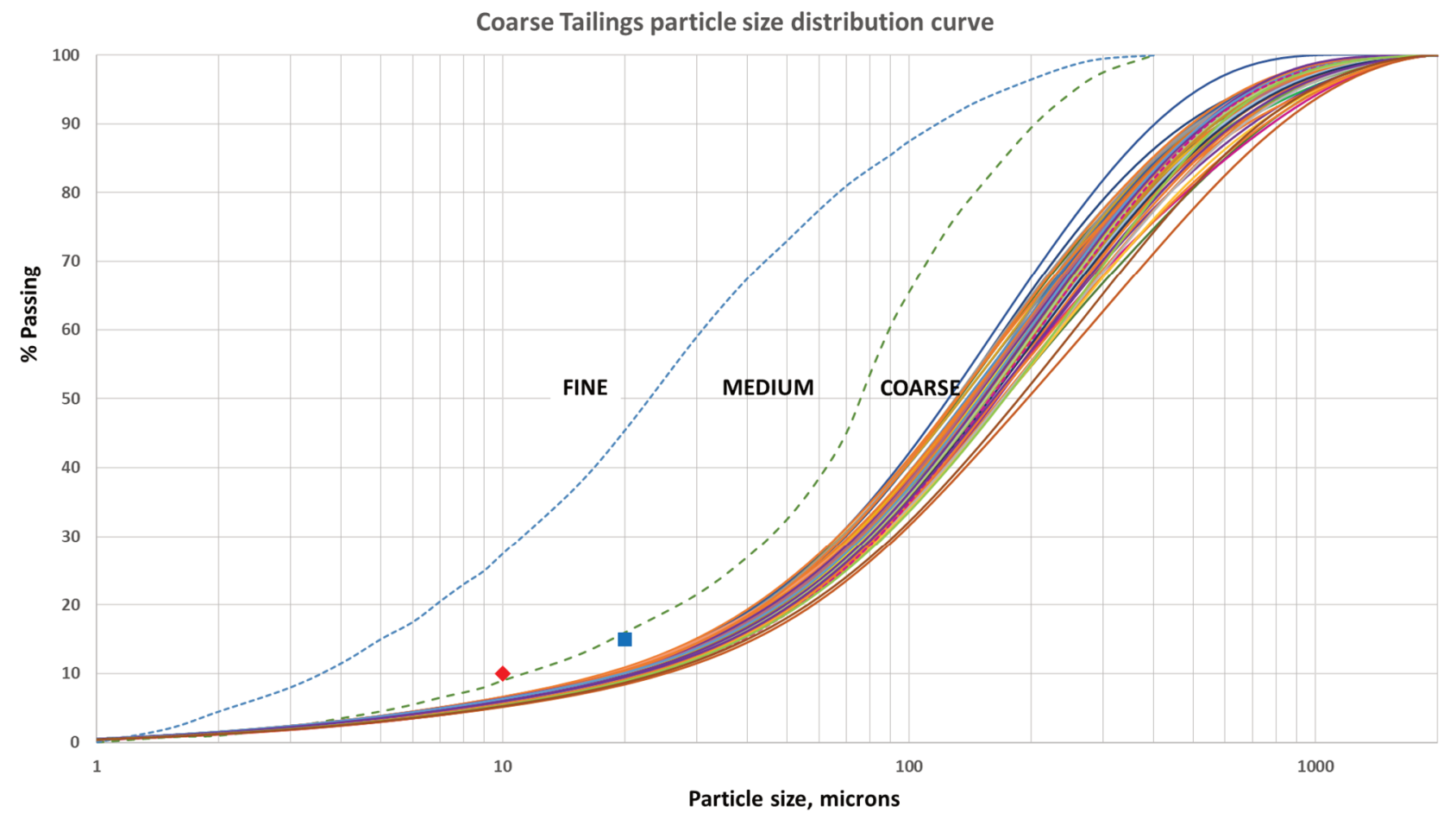

Figure 22 Stockpile tailings particle size distribution

\subsubsection{Tailings mineralogical composition}

The mineralogical composition of Mavres Petres coarse tailings, using quantitative X-ray diffraction (XRD) method, has been completed recently at a laboratory in Australia. In total, 15 samples were submitted for analysis (Table 1). 
Table 1 Stockpile tailings $\mathrm{X}$-ray diffraction results

\begin{tabular}{|c|c|c|c|c|c|c|c|c|c|c|c|c|c|c|c|}
\hline Date & $\frac{\underset{N}{N}}{\text { N }}$ & 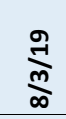 & 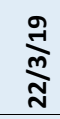 & 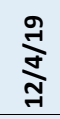 & $\underset{⿱ 亠}{\stackrel{n}{n}}$ & 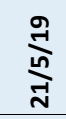 & 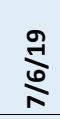 & $\underset{\hbar}{\stackrel{2}{\hbar}}$ & 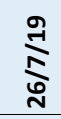 & 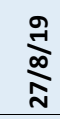 & 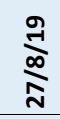 & 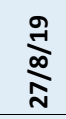 & $\frac{\sigma}{\sigma}$ & $\underset{ }{\stackrel{2}{\sigma}}$ & $\underset{ન}{\stackrel{\sigma}{\sigma}}$ \\
\hline \multicolumn{16}{|l|}{ Mass (\%) } \\
\hline Pyrite & 41 & 39 & 42 & 38 & 40 & 32 & 40 & 34 & 34 & 38 & 39 & 35 & 37 & 40 & 34 \\
\hline Arsenopyrite & 7 & 7 & 7 & 8 & 8 & 11 & 8 & 8 & 9 & 9 & 9 & 7 & 7 & 11 & 8 \\
\hline Clay mineral & $<1$ & $<1$ & $<1$ & $<1$ & $<1$ & 0 & $<1$ & $<1$ & $<1$ & $<1$ & $<1$ & $<1$ & $<1$ & $<1$ & $<1$ \\
\hline Kaolinite & $<1$ & $<1$ & $<1$ & $<1$ & $<1$ & $<1$ & 0 & 1 & 1 & $<1$ & $<1$ & $<1$ & $<1$ & $<1$ & $<1$ \\
\hline Chlorite & 2 & 2 & 1 & 1 & 1 & 2 & 2 & $<1$ & $<1$ & 1 & 1 & 1 & 1 & 1 & 1 \\
\hline $\begin{array}{l}\text { Annite - biotite - } \\
\text { phlogopite }\end{array}$ & 1 & 1 & $<1$ & 1 & 1 & $<1$ & $<1$ & $<1$ & $<1$ & 1 & 1 & 1 & $<1$ & $<1$ & $<1$ \\
\hline Muscovite & 1 & 1 & 1 & 1 & 1 & 1 & 1 & 1 & 1 & 1 & 1 & 1 & 1 & 1 & 1 \\
\hline Calcic amphibole & $<1$ & $<1$ & $<1$ & $<1$ & $<1$ & $<1$ & $<1$ & $<1$ & $<1$ & $<1$ & $<1$ & 0 & $<1$ & $<1$ & $<1$ \\
\hline Clinopyroxene & 0 & 1 & 0 & 0 & 0 & 0 & 0 & 0 & 0 & 0 & 0 & 0 & 0 & 0 & 0 \\
\hline Plagioclase & $<1$ & 1 & $<1$ & $<1$ & 1 & $<1$ & $<1$ & 1 & 1 & 0 & 0 & 0 & 0 & 0 & 0 \\
\hline $\begin{array}{l}\text { K-feldspar and/or } \\
\text { rutile }\end{array}$ & $<1$ & 1 & 0 & 0 & 0 & 1 & $<1$ & 0 & $<1$ & 0 & 0 & 0 & $<1$ & 0 & $<1$ \\
\hline Quartz & 11 & 10 & 8 & 12 & 11 & 10 & 14 & 13 & 13 & 11 & 11 & 11 & 12 & 7 & 10 \\
\hline $\begin{array}{l}\text { Gypsum and/or } \\
\text { Bassanite }\end{array}$ & $<1$ & $<1$ & 1 & 1 & 1 & $<1$ & $<1$ & 0 & 0 & 1 & $<1$ & $<1$ & 1 & 1 & 1 \\
\hline Dolomite group & 6 & 6 & 5 & 6 & 5 & 7 & 7 & 3 & 4 & 4 & 3 & 4 & 4 & 4 & 4 \\
\hline Calcite & 9 & 10 & 9 & 8 & 8 & 10 & 10 & 8 & 9 & 7 & 7 & 7 & 7 & 8 & 8 \\
\hline Amorphous material & 21 & 22 & 25 & 25 & 22 & 25 & 16 & 30 & 26 & 27 & 27 & 32 & 28 & 25 & 31 \\
\hline
\end{tabular}

The XRD results generally indicate an expected range of minerals for a carbon replacement deposit. Pyrite $(32-42 \%)$ is the dominant mineral with amorphous material accounting for $16-32 \%$. The minor minerals include arsenopyrite (7-11\%), quartz (7-14\%), ankerite-dolomite (3-7\%) and calcite $(7-10 \%)$. There is a limited amount of minerals that can have adverse effects on rheology and strength of backfill. These are less than $2 \%$ for chlorite and less than $1 \%$ each for clay mineral, kaolinite, chlorite, muscovite, biotite and gypsum and/or basanite minerals.

\subsubsection{Backfill strength}

Using analytical solutions, BGMC has estimated a design UCS of $0.5 \mathrm{MPa}$ for vertical exospores and 1.0-2.0 MPa for undercut exposures. However, the submitted technical study for Mavres Petres has specified target backfill strengths of $1.0 \mathrm{MPa}$ before vertical exposures and strength of $4.0 \mathrm{MPa}$ at 28 days cure age, combined with a restriction in cement content which should not be less than $10 \%$ by solids weight, for all type of exposures.

There is significant opportunity for Mavres Petres to adopt more realistic design strengths based on the planned stope exposures and production schedule in order to ensure the stability and long-term economic viability of the mine.

\section{$5 \quad$ Backfill mix optimisation}

A comprehensive program of test work, using various cement types (CEM II/32.5, CEM II/42.5, CEM I/42.5, Sulphate resistant cement) was completed at Mavres Petres in September 2019. Test work indicated that cement, CEM II/32.5, did not reach the permit mandated design UCS of $4.0 \mathrm{MPa}$ at 28 days at economic cement rates. The cement screening test results indicated cement CEM I/42.5 was best performing among the cement types tested.

Subsequent mix optimisation test work was completed using CEM I/42.5 cement mixed at various solids density (with the aim to determine the limit of maximum placed solids content that can be delivered) and 
cement rates using different tailings in order to determine the optimal operating range for the backfill plant while meeting the mandated backfill strength at the lowest cement rate (Figure 23).

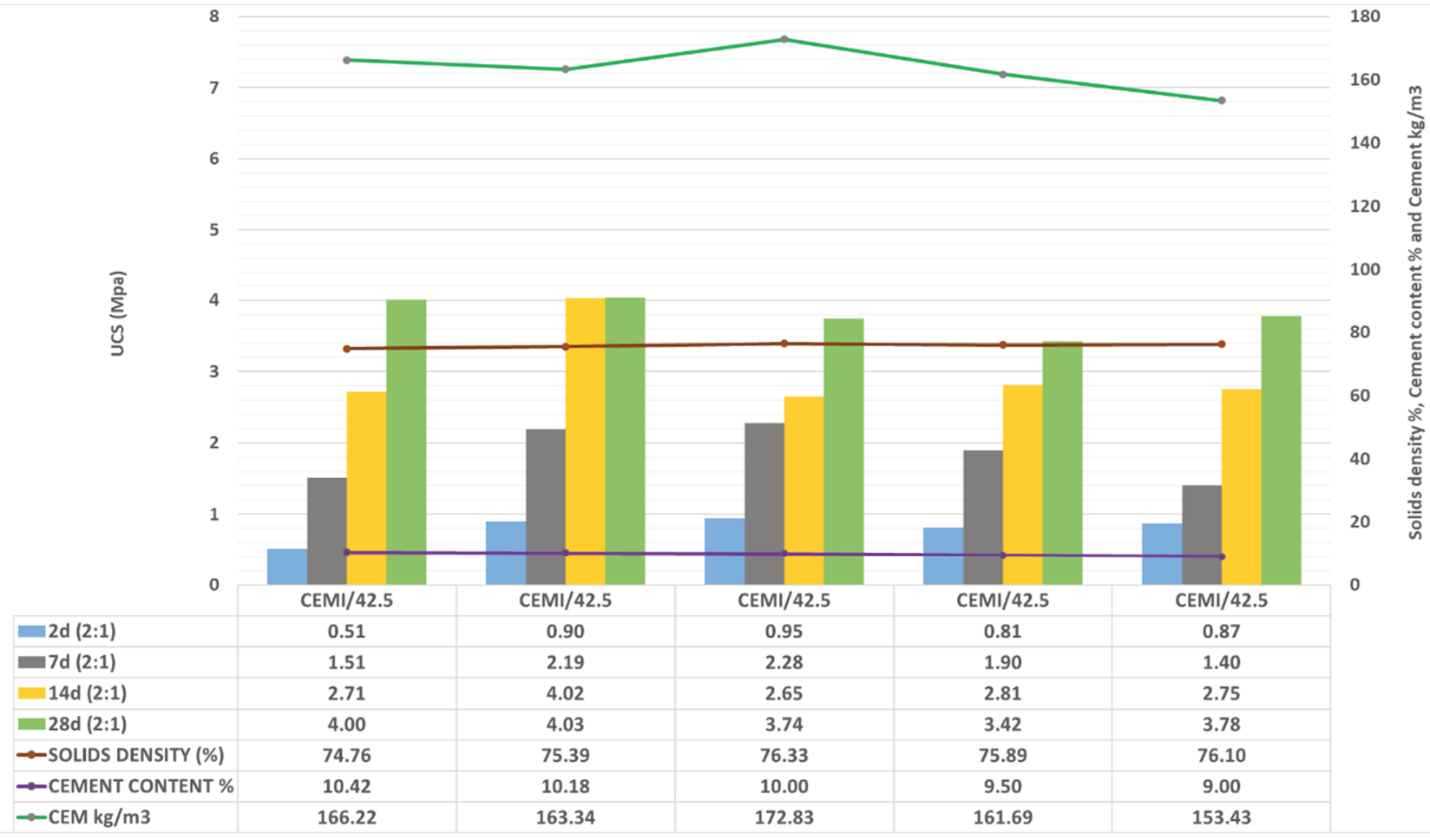

Figure 23 Mix optimisation results

A decision was made to switch to CEM I/42.5 in September 2019. The current backfill mix design is based on $1.0 \mathrm{~m}^{3}$ per batch, operating solids density of $76 \%$ and cement rate of $10 \%$.

Table 2 compares the previous and current backfill mix design and delivery rate at Mavres Petres mine.

Table 2 Comparison of previous and current mix design

\begin{tabular}{lll}
\hline Parameter & Previous mix design & Current mix design \\
\hline Batch size $\left(\mathrm{m}^{3}\right)$ & 0.7 & 1.0 \\
Solids content $(\% \mathrm{~m})$ & $73-74$ & 76 \\
Cement type & CEM II/32.5 & CEM $/ / 42.5$ \\
Cement $(\%)$ & $16-16.5$ & 10 \\
Cement rate $\left(\mathrm{kg} / \mathrm{m}^{3}\right)$ & 255 & 170 \\
Uniaxial compressive & 4.0 & $>4.5$ \\
strength 28 day (MPa) & & \\
\hline
\end{tabular}

\section{Discussion and concluding remarks}

Significant progress has been made since December 2018 for upgrading and optimising the existing backfill system at Mavres Petres. A systematic holistic review and systems engineering approach was adopted in order to improve backfill plant, backfill production, backfill QC, backfill delivery, and placement. The ongoing efforts have culminated in a safe and optimised backfill system that can now deliver consistent backfill quality meeting the permit strength demands at economic rates, as well as mining and schedule requirements. 
Due to the constraints imposed by the environmental impact assessment on backfilling at Mavres Petres mine, there is a requirement that the final backfill strength must reach a UCS of $4.0 \mathrm{MPa}$ at 28-day cure age and the cement content should not be lower than the limit of $10 \%$. By developing and testing an extensive series of mix recipes, using various cement types and solids density and tailings types, it was possible to achieve the strength demands at economic cement rates while maintaining workability and pumpability of the hydraulic backfill.

The mandated target 4.0 MPa UCS at 28 days cure age for all exposure strengths is high and is not aligned with the prevailing mining conditions at Mavres Petres mine. Adopting more realistic strength design $(0.5-2.0 \mathrm{MPa})$ based on the planned exposures is paramount for maintaining the long-term economic viability of the mine.

\section{Acknowledgement}

The authors appreciate Hellas Gold S.A. and Mavres Petres mine management for their support and permission to publish this paper. Special thanks are also due to mine technical and operations teams for help with collection of data presented in this paper.

\section{References}

Backfill Geotechnical Mining Consultants Pty Ltd 2019, Mavres Petres Backfill Review and Optimisation, Backfill Geotechnical Mining Consultants Pty Ltd, internal consulting report to Hellas Gold.

Potvin, Y, Thomas, EG \& Fourie, AB (eds) 2005, Handbook on Mine Fill, Australian Centre for Geomechanics, Perth. 
